\title{
The effect of job rotation intervals on muscle fatigue - lactic acid
}

\author{
Filus, Rodrigo,", Okimorto, Maria Lucia \\ *Mechanical Engineering Department - PGMEC - UFPR - Brazil. \\ ${ }^{\mathrm{b}}$ Production Engineering Department - Ergonomic Lab- UFPR - Brazil
}

\begin{abstract}
This study is a job rotation comparative that aims to define the properly scheme to be in use at the time it is performed. As fatigue plays directly against the work results this comprehensive study about the action of lactic acid over workers at different jobs and strength demand was realized to find the best methodology to maximize those rotations.
\end{abstract}

Keywords: Job Rotation, lactic acid, effort

\section{Introduction}

Deep changes induced by current increase of production and low-cost demands to work as well as the introduction of new technologies to it, have forced workers, mostly from developing countries, to change their way to work. This scenario with new concepts of work speed, rest and commitment with the final results has interfered directly with workers' heath, commonly with their musculoskeletal system. Intensely involved in this context, job rotation has become a common approach to reducing the incidence of work related musculoskeletal injury risk.

As it provides the possibility of alternation of the biomechanical demand whilst working $[1],[2],[3]$, in theory, job rotation could lessen the occurrence of that kind of disorder. When measurement method is properly applied, lactic acid used as a physical fatigue indicator might make possible job rotation to be implemented in several segments of a company, by defining issues such as the proper intervals on duty, the scheme to be followed and the right alternation of muscular groups.

This study hence evaluate job rotation schemes performed in shorter intervals (high jobs swaps) and its compatibility in muscular groups exchange as well as the consequences of physical fatigue risk, applying acid lactic as the indicator of disturbance. Already an important tool to ergonomics, it is expected for this accomplishment to make the sharing of tasks easier, work more pleasant and efficient, contributing so to companies and workers correlation.

\section{1 - Fatigue (muscle weakness)}

Fatigue may be defined as any reduction of the capacity to perform a voluntary effort [4],[5],[6], It is the result of long periods of continuous physical and/or mental exertion, which induces reversible reduction of the person's work capacity and so affecting task performance. It is caused by a complex group of factors with cumulative effects [7].

\section{2 - Fatigue prognosis and quantification}

As fatigue reduces muscular strength, causes discomfort and pain, it is believed that in the long run it increases the potential for health disorder and injuries to occur, therefore, fatigue is important to be quantified to set limits for muscular load. Nowadays, several quantification and qualification methodologies to evaluate fatigue can be found.

However, qualitative analysis may not be quantified in numbers, but just qualified or classified as it depends on a person's own evaluation to be performed. On the other hand, a great number of both invasive and non-invasive procedures for quantitative

\footnotetext{
*Corresponding author. E-mail: rodrigo.filus@ergox.com.br.
} 
evaluation have already been developed to quantify and determine fatigue origin.

Grandjean [8] observed that, based on the fatigue measurement, it is possible to understand the level of human exhaustion at work, and also measure the human organism reaction to different workloads. However, according to the author it is important to notice that "there is not nowadays any direct quantitative evaluation method of fatigue status. Thus as all applied methods up to these days could only measure certain signs of the fatigue; they can only be appraised as fatigue indicators".

\section{Lactic acid and the Lactate test}

Lactic acid is a weak acid produced by the organism through a chemical process that requires no oxygen (anaerobic metabolism). It is a contributive factor for muscular cramps and it is usually removed from the blood by the liver. Its buildup in the body results in a state called lactic acidosis. The lactic acid test is used as an indirect oxygen level measurement in body tissues that establish the cause and the course of lactic acidosis.

\section{1 - Lactic acid threshold.}

Denadai [9] observed that, regardless of concerns and controversies about methodologies and terminologies in use to identify lactate development during progressive exercise, many studies had already concluded that anaerobic threshold is in fact the most appropriate lactate indicator, overcoming even VO2. Thereby, as lactic acid accumulates in the blood during exercise any eventual reduce of $\mathrm{pH}$, which takes it to a level it starts interfering with the enzymatic action, might lead to fatigue. In addition, as the amount of ATP produced by glycolysis is too small if compared with the amount provided by Krebs cycle, the substratum for the reaction becomes then estricted either to the glucose supplied by the blood's sugar or to the glycogen stocks in the muscle. Hepatic glycogen contributes to the sugar present in blood stream, however it is limited in quantity. Muscular glycogen cannot move itself in the blood stream in a way that the anaerobic capacity of each muscle is limited to its own glycogen content.

Farinati and Monteiro [10] stated that physical training could greatly change both production and elimination of lactate in muscles when specific work is executed on them. Exerts established that a physical training process which produces a lactate concen- tration of $4 \mathrm{mmol}$ is great to reduce the concentration of this chemical compound to level below the usual standards [11], [12]. Wells [13] proposed the use of the average lactate concentration at habituated exercises to establish training load. He also developed a three-level effort intensity classification related to lactate concentration at that level, as follows: Light work, level that doesn't increase the lactate; Heavy work, level that produces an increase of about 1.5 to 2 times; and Overload, level that produces an increase of up to 5 times in lactate concentration found at the habituated exercises level.

Not far from that, Liesen [12] by the studies of Mader, et al. [12] concluded that by comparing levels of arterialized lactate with conditions to acquire technical abilities and making good use of tactics:

1) Levels of up to $2 \mathrm{mMol} / 1$ are suitable to attain new techniques, to work any variation and to the practice of any tactical element;

2) Levels of up to $6 \mathrm{mMol} / 1$ are less favorable to attain new techniques as it depends on one's good resistance and muscular potency;

3) Levels above $6 \mathrm{mMol} / 1$ affect the perception and the responses are wasteful under the energetic point of view.

FOX, et al. [14] observed that women tend to have lower levels of lactic acid in the blood after a maximum exercise when compared with men. A way to determine lactate threshold is through running test. Individual test compound of 5 minutes shoots in different speeds, from 4.0 to $6.1 \mathrm{~m} / \mathrm{s}$ for example, in the properly track would bring great result.

\section{Job Rotation}

Firstly made up to overcome issues concerning to absenteeism [15] and productivity decrease [16], job rotation has become a comprehensive tool for companies to maximize their work process by reducing the risks connected to them.

Slack, et al. [17] observed that when an eventual increase in work tasks was limited by the technological level of work process, taking turns (i.e. periodically move individuals among different groups of tasks to provide some variation in their activities) turned to be a possible alternative to be taken into account. Several studies have already reported positive results related to those variations and pauses during work, however, only a few have included job rotation at all. 
Henderson, [18], Canadian Center for Occupational Health and Safety, [19]; and Kuiser, et al, [20] affirm that the use of those taking turns or swapping schemes based on simple post position change are to be considered job rotation hence supposed to guarantee ergonomic risk decrease.

Kuiser, et al, [20] analyzed both advantages and disadvantages of job rotation regarding to manual load rising. They concluded that the appropriate outline of a job rotation scheme, taking into account ergonomic aspects, would improve tasks performance. Anne Gerling, et al, [21] noticed that the required content necessary to outline a job rotation scheme might naturally be taken from analysis of previous evaluations, and also that the focus, during this process, have to be seriously placed upon the reduction of the biomechanical demand of work.

Ellis, [3] and Mac Leod and Kennedy,[16] concluded that either the shift increase or taking turns monotonous or repetitive work might indeed decrease boredom up to a certain level. But differently from what is expected the adaptation capacity of workers to difficult work situation is hardly reached.

\section{Perception complexity}

Grandejean [7] affirmed that the evaluation of subjective sensations may

be made up from special surveys. This way, we have bipolar questions standing out any sort of questionnaire due to the ease with which they may be applied and also understood by the people. Through these questionnaires, the respondent is asked to mark responses between the two opposite ends of a scale that states how they feel at that moment.

\section{5 - Methodology}

LEAP 1 - Gettting to know the types of job rotation within companies in Curitiba and surroundings through questionnaire application to find out their records concerning to job rotation.

LEAP 2 - Define an industrial sector suitable to implement job rotation scheme proposed. Evaluate Positions. Collect lactic acid.

LEAP 3 - Collect fatigue indicators data and compare to the quantitative lactic acid results.

\section{1 - Work group outline}

The following criteria were taken to define the work group: not more than 11 workers would be part of it due to procedures cost; the chosen industry would have an assembly line; workers would have at least 6 months experience in the assembly line, technical know-how over all other required positions, average age ranging between 20 and 30 years old and could not be a sportsperson; work cycles should be shorter than 90 seconds. By mean of this, a section of a home appliances industry was define as the most appropriate to hold the actions and so a work group was established and right after divided into two, one to collect lactic acid after each position's rotation and the other to collect it at the beginning and end of the shift.

\section{2 - Biomechanical process related to the job}

It is believed that biomechanical interchanges during work are necessary to avoid muscular overcharge or any associated fatigue and to reduce levels of lactic acid in the workers blood. The importance of this comes from the fact that job rotation might be only made viable, in view of biomechanics, in case an alternation of the charged muscular groups round all jobs could be performed.

\section{3 - Outline a job rotation scheme.}

Information brought by the literature and all in company surveys made possible to define the proper job rotation scheme to be applied in the chosen work group. As a result, actions were set as follows: rotations were made by swapping jobs considered easy, moderate and difficult, in view of biomechanics; and muscular groups were always alternated every rotation. The scheme also alternate rotation length to find out their effectiveness as regards the accumulation of lactic acid, intervals of one, two and three hours were tested subsequently.

\section{4 - Intervals}

Rotation intervals followed the next sequence: During the first week rotation intervals took an hour length, and at the end of this week the lactic acid levels were measured. During the second week rotation intervals took two working hours with lactic acid level measurement again being made only at the end of the week. The same happened during the third week, however, rotation intervals took three hours.

The reasons for which job rotation had to be performed all over the weeks and the lactic acid levels were only measured by the end of them were that workers had to be fully adapted to shifts and to the 
kind of work they did for results to represent things in the way they were accurate and true to life.

\section{5 - Approach to work group}

After defining intervals and sequence training must be provided to all engaged staff with the purpose of clarify the research goals and also to explain the reasons for following the proper job rotation sequence.

5.6 - Lactic Acid collection and job rotation scheme

The lactic acid collections were made in two different ways as follows:

a) Collections at the beginning of shift and after each positions swap, regardless of intervals took one, two or three hours. These collections were made by half of the work group, and this group was supposed to take only a restricted number of jobs from the set under study.

b) Collections at the beginning and at the end of the shift, regardless intervals took one, two or three hours. These collections were made by the other half of the work group, and this group was supposed to take only a restricted number of jobs from the set under study.

\section{7- Lactic Acid collection and fatigue sings}

Follow-up each worker regarding their muscular fatigues status is necessary in order to make possible a comparison to the metabolic results. Thus an interval scale ranging from zero to ten to measure their muscular fatigues perception was adopted. In it zero was considered no fatigue and ten maximum fatigues.

\section{Results}

6.1 - Survey results (In company survey Figure 1).

\section{2 - Job rotation scheme.}

After a comprehensive analysis of the biomechanical risk related to the jobs under study, a properly division of groups as well as the outline of the exactly scheme could be found. The table below illustrates it

"Table 1" brings the work group division, this way, group $\mathrm{A}$ in yellow (jobs 1, 2, 8, 9 and 10) was the one collected lactic acid at the beginning of shift and after each position swap, and group B in blue (positions 3, 4, 5, 6, 7 and support) the one collected it at the beginning and at the end of the shift. Job rotation schemes were then defined to balance biomechanical level of jobs performed by both groups.

\section{Survey results (In company survey)}

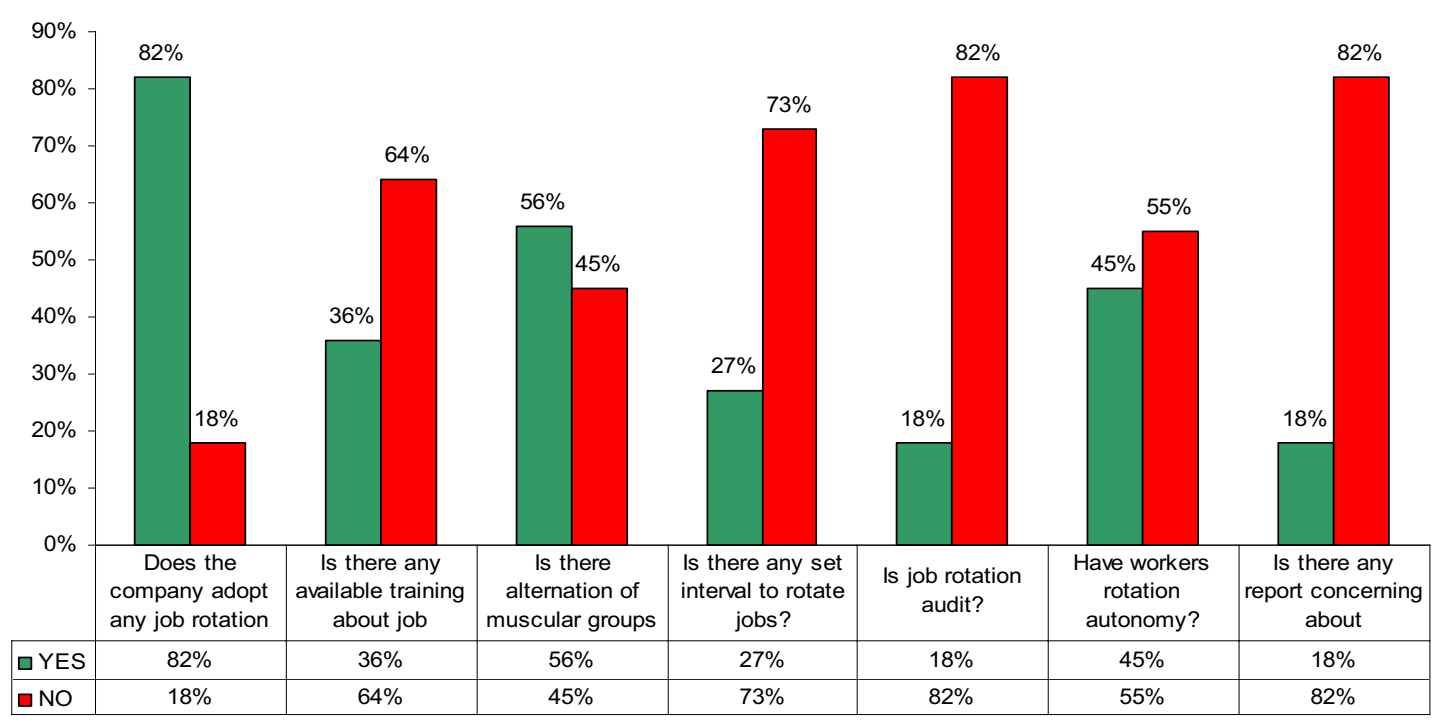

Figure 1. Job rotation survey 


\begin{tabular}{|c|l|c|}
\hline Job & \multicolumn{1}{|c|}{ Activity } & \multicolumn{1}{|c|}{$\begin{array}{c}\text { Next } \\
\text { position }\end{array}$} \\
\hline $\mathbf{1}$ & $\begin{array}{l}\text { Stick insulation material "A" and "B" on the back of } \\
\text { the cover. - MEDIUM }\end{array}$ & $\mathbf{1 0}$ \\
\hline $\mathbf{2}$ & $\begin{array}{l}\text { Foam on specific contour assemble the lamp cover } \\
\text { Set up material in the production line - EASY }\end{array}$ & $\mathbf{1}$ \\
\hline $\mathbf{8}$ & Silicon on the lower part (carrousel) - DIFFICULT & $\mathbf{2}$ \\
\hline $\mathbf{9}$ & Cut blue PP tape off to fast internal parts - EASY & $\mathbf{8}$ \\
\hline $\mathbf{1 0}$ & Place the control box. - DIFFICULT & $\mathbf{9}$ \\
\hline $\mathbf{3}$ & $\begin{array}{l}\text { Place the seal rubber, put in the engine fan and screw } \\
\text { it - DIFFICULT }\end{array}$ & $\mathbf{7}$ \\
\hline $\mathbf{4}$ & $\begin{array}{l}\text { Place the front cover of the steamer, screw and stick } \\
\text { tapes. EASY }\end{array}$ & $\mathbf{4}$ \\
\hline $\mathbf{5}$ & $\begin{array}{l}\text { Apply silicon on the higher part (Freezer) } \\
\text { DIFFICULT }\end{array}$ & SUPPORT \\
\hline $\mathbf{6}$ & $\begin{array}{l}\text { Place the Freezer shelf, bi-parted shelf, balancing } \\
\text { cover e apply scotch tape. MEDIUM }\end{array}$ & $\mathbf{6}$ \\
\hline $\mathbf{7}$ & Place vegetables drawer - EASY \\
\hline Support & $\begin{array}{l}\text { Support assemble line. Separate specific material. } \\
\text { EASY }\end{array}$ \\
\hline
\end{tabular}

(Table1) - Biomechanical level of jobs, work group division and job rotation scheme.

6.2.1 "Group A" lactic acid end result versus muscular fatigue perception.

After each collection of lactic acid workers answered a survey about muscular fatigue perception. Workers from this group were submitted to rotation intervals of 1 and 2 hours, and not 3 hours as its results were likely to be same as those found in group $\mathrm{B}$ (collections at the beginning and at the and of the work shift). (Lactate $(\mathrm{m} / \mathrm{mol})$ evolution in $1 \mathrm{~h}$ rotation interval).

"Figure 2" identify each worker and show their lactate evolution after each working hour. Collections were made after each activity accomplishment (1h interval) during half shift. Conclusions were that there is either an increase or a decrease of lactate after each rotation, what shows that alternations between difficult and easy jobs tend to produce a decrease of acid lactic hence lower tendency to muscular fatigue.

"Figure 3" shows lactate evolution for $2 \mathrm{~h}$ rotation intervals. The initial lactate levels correspond, in theory, to the levels of the $1 \mathrm{~h}$ job rotation group. However, this graphic shows a considerable increase in the lactate levels when compared to the previous one.

The levels of 01:00 pm were not collected due to lunch break, this way next collection only happened at 03:00 pm. For a better elucidation let's take worker $\mathrm{H}$ lines (Figure 4). 


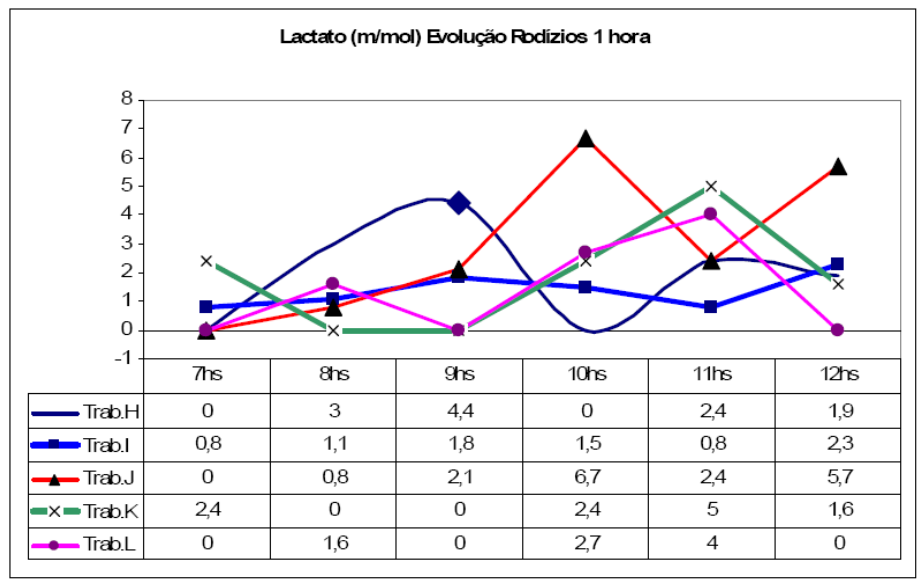

(Figure 2) Lactate $(\mathrm{m} / \mathrm{mol})$ in 1 h rotation interval.

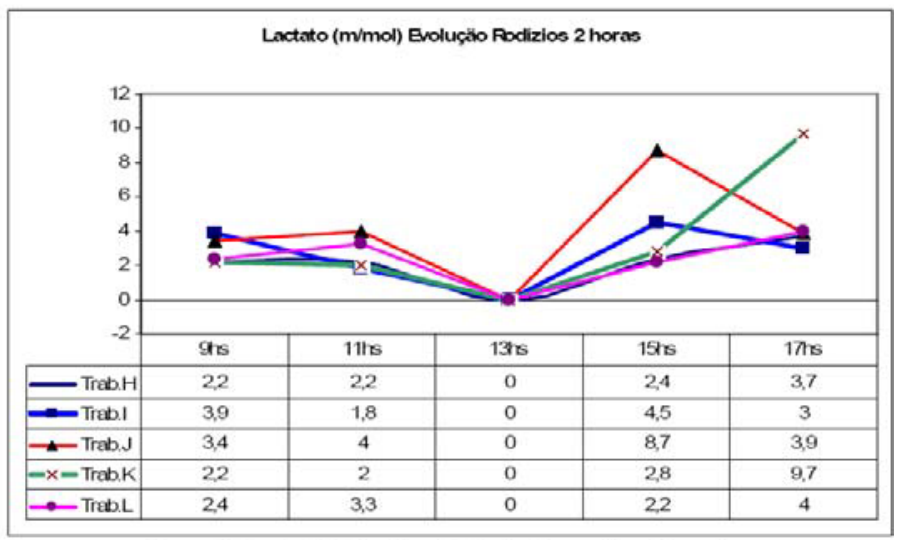

(Figure 3 ) Lactate $(\mathrm{m} / \mathrm{mol})$ evolution in $2 \mathrm{~h}$ rotation interval.

Lactate $(\mathrm{Mmol}) 1$ and 2 hours rotation intervals - Worker $\mathrm{H}$

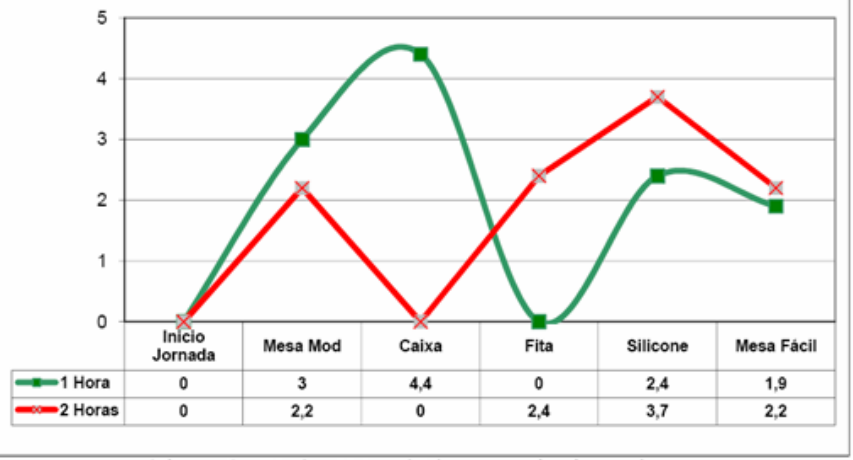

(Figure 4) - Worker $\mathrm{H} 1$ and 2 hours rotation intervals. 
Statistical Analysis verified that the difference between the levels of lactic acid from the easy (tape) and the difficult (silicon) jobs is significant. In other words, the levels of lactic acid in the difficult job are considerably larger than in the easy. Besides, it is possible to observe that there is a tenuous coincident line between the perception and quantitative data (figure 5).
In statics view, however, it is noticed that there is feeble concordance between the worker's perception and the quantitative information, which can be attested on the fact that there are workers with a strong concordance (worker $\mathrm{J}$ ) and workers with a low concordance (worker $\mathrm{H}$ ).

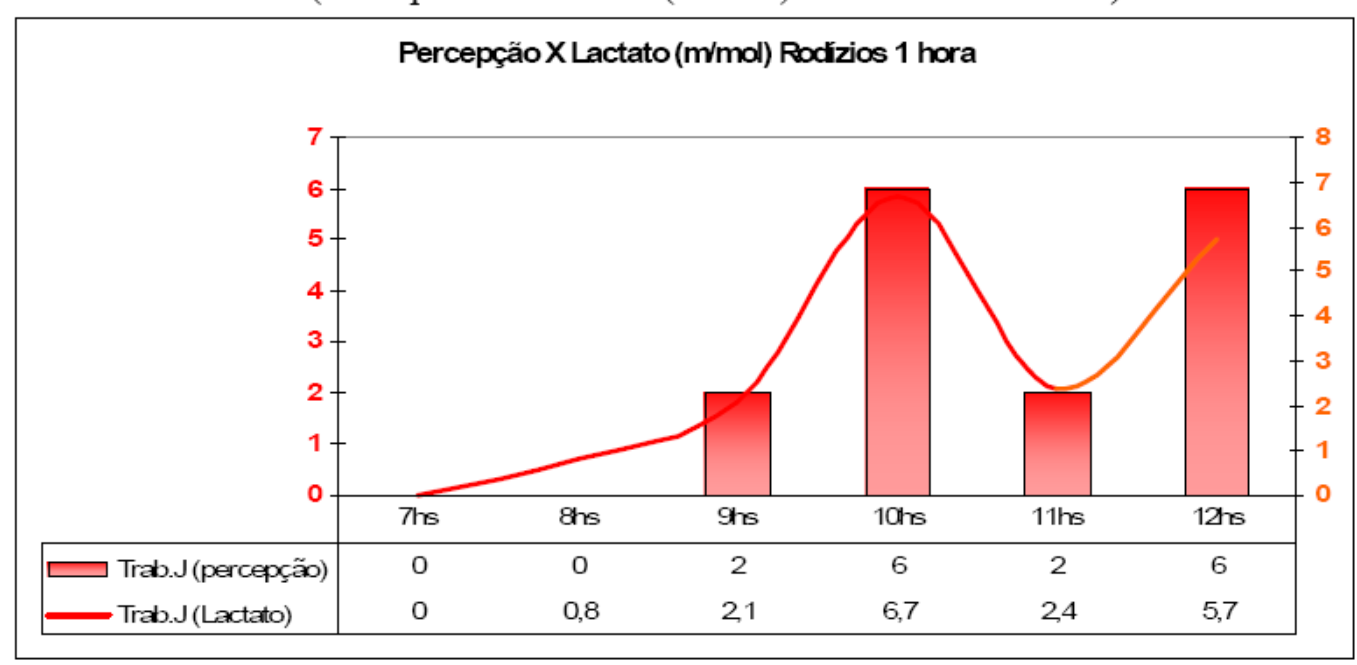

(Figure 5) - Perception x Lactate 1 h rotation interval.

6.2.2 “Group B” lactic acid end result versus muscular fatigue perception.

Workers from "group B" were addressed with letters from "A" to " $F$ " and their information collection process differed from "group A" as it followed this sequence: collections at the beginning of the shift; after 1, 2 and 3 working hours and at the end of the shift
"Figure 6" shows lactic acid levels after each rotation. After comparing results it is possible to see a considerable lactate increase at the $3 \mathrm{~h}$ rotation lines. Jobs and levels of lactate at the beginning and end of the shift are found below. However, notice that the following information does not correspond to the same worker as jobs were already swapped. The difficulty of each job is directly connected to the level of lactate found, independent of the worker in charge. 


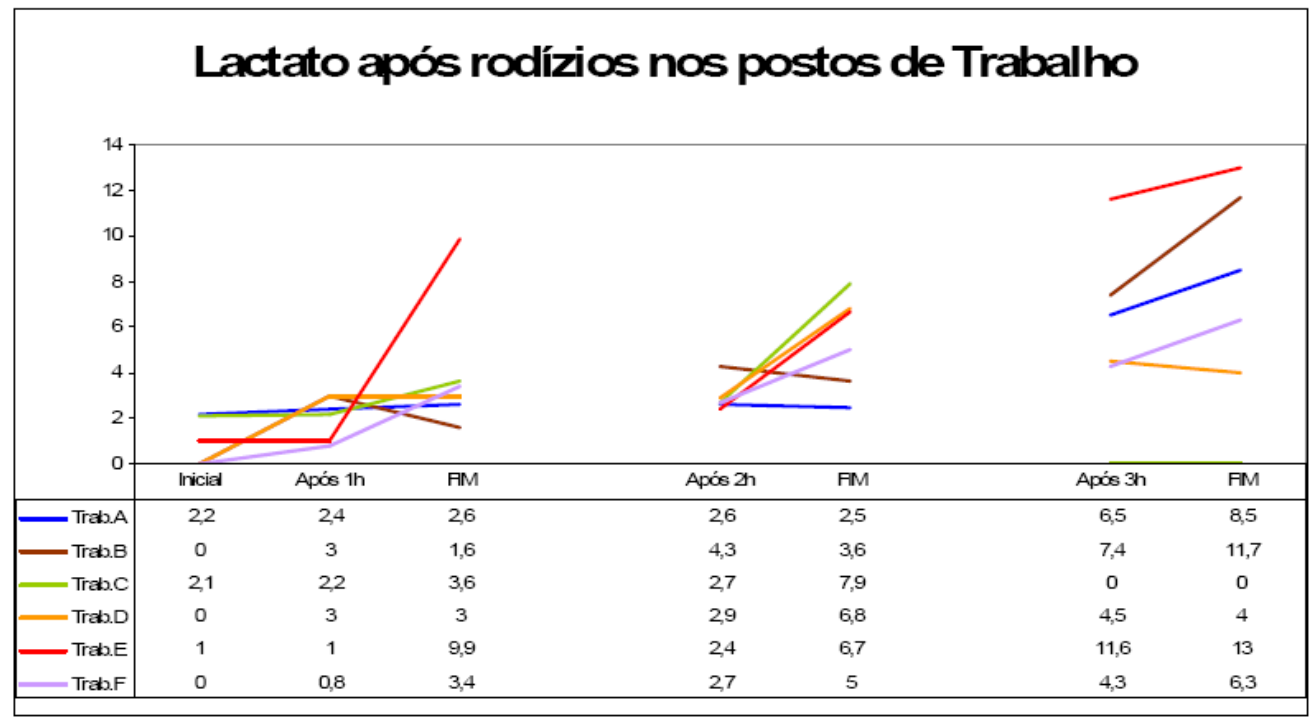

(Figure 6) - 1h, $2 \mathrm{~h}$ and $3 \mathrm{~h}$ lactate comparative

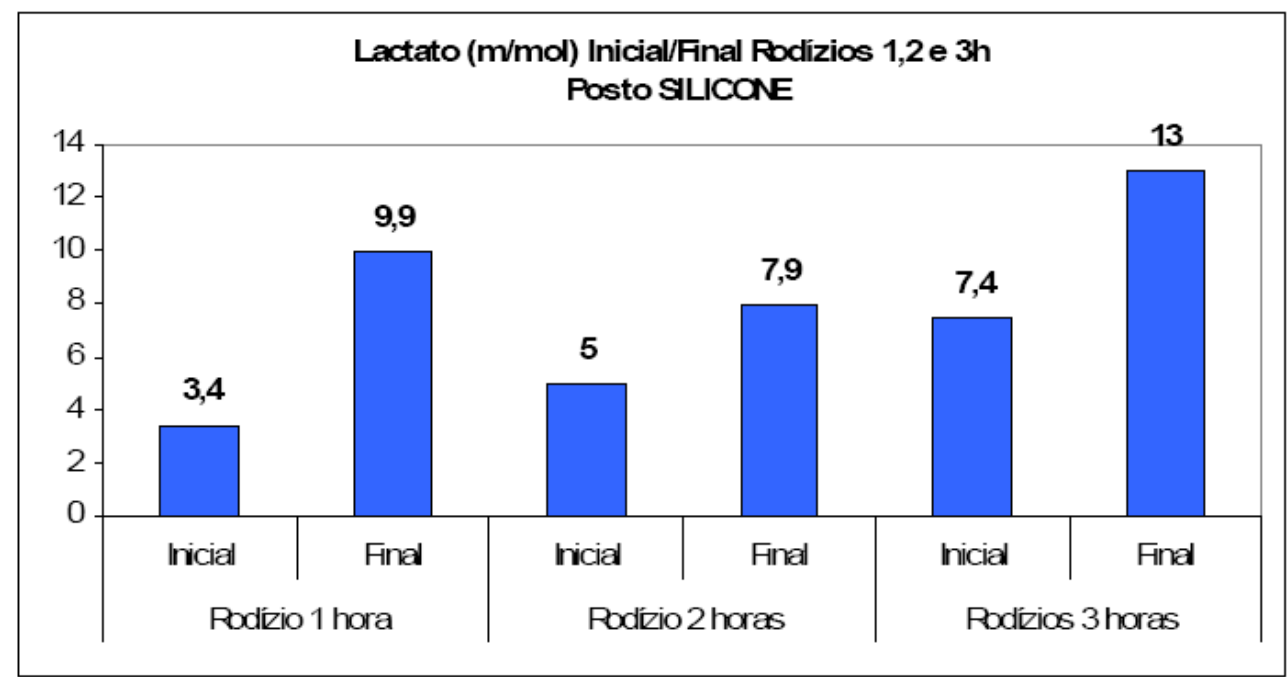

(Figure 7) - Comparative at SILICON (job 5).

The figure 7 brings out information about job which is called Silicon. Activities from this position are considered to be difficult. This job presents several inadequate posture points, what speed muscular fatigue process up. Graphic also shows that the rotations of $3 \mathrm{~h}$ can raise lactate concentration up to $70 \%$, depending on the activities imposed.

"Figure 8" brings out information about job called Tape. Activities from this position, o the other hand, are considered to be easy. This job seldom presents inadequate posture points.

The concentrations of lactic acid are also considerably raised for rotation of $3 \mathrm{~h}$. The issues at this job, concerning to workers and intervals, are the same as those from Silicon, therefore the interval information does not necessarily correspond to same worker. 


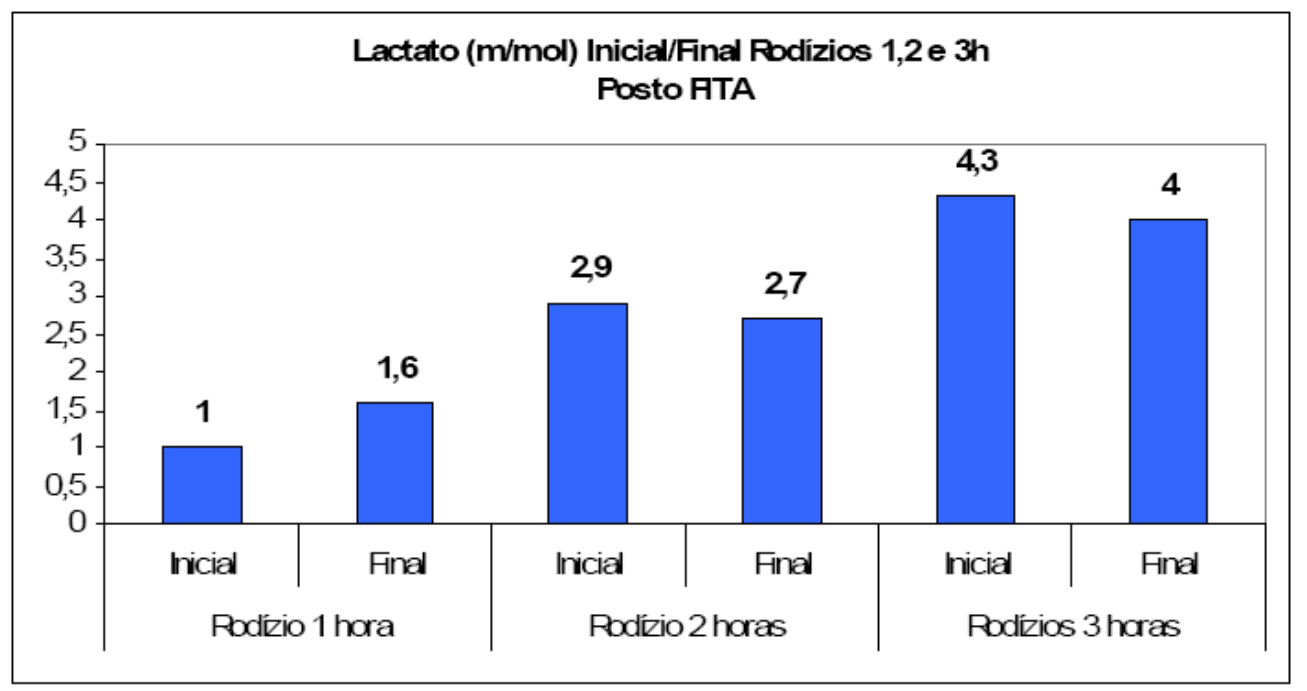

(Figure 8) - Comparative at TAPE (job 4).

6.3 Statistical results relative to lactic acid and its collection in rotations made after $1 \mathrm{~h}, 2 \mathrm{~h}$ and $3 \mathrm{~h}$.

\subsubsection{Test number 2- MANNWHITNEY test $U$}

This test was made to compare the group submitted to rotations of $1 \mathrm{~h}$. Therefore it is possible to say that the levels of lactic acid differ according to job rotation intervals.

\subsubsection{Test number 3- MANNWHITNEY test $U$}

The third test was made to compare groups submitted to rotations of $2 \mathrm{~h}$ with those submitted to $3 \mathrm{~h}$. It is possible to say that the levels of lactic acid differ in job rotation of $2 h$ and $3 h$ intervals.

\subsubsection{Test number 4- WILCOXON test}

The fourth test was made to compare groups submitted to rotations of $1 \mathrm{~h}$ with those submitted to $2 \mathrm{~h}$. It is possible to say that the levels of lactic acid do not differ in job rotation of $1 \mathrm{~h}$ and $2 \mathrm{~h}$ intervals.

6.3.4 Statistical results relative to the activities complexity at workplaces.

The aim of these tests was to compare an easy job to a difficult one showing that the perception evaluation is compatible to the job real presented muscular fatigue. For the job evaluation the levels of lactic acid measured in job rotation of $1 \mathrm{~h}$ and $2 \mathrm{~h}$ intervals were considered. The levels of lactic acid differ between the Tape and Silicon positions.

\section{Conclusions}

It is noticed that the terms production and health are interlinked in business nowadays, therefore, according to the premise that when lactic acid, as indicator of muscular fatigue, is correctly measured it makes job rotation procedures viable, by the definition of its ideal scheme and the properly alternations of muscular groups, it can be concluded that through the reliability of the presented results that job rotations schemes of $1 \mathrm{~h}$ and $2 \mathrm{~h}$ intervals produce less lactic acid than those longer length

\section{References}

[1] Jonsson, B., 1988b. Electromyographic studies of job rotation. Scand J Work Environ Health. Suppl. 1, 108-109.

[2] Roquelaure Y., Mechali S., Dano C., Fanello S., Benetti F., Bureau B., Mariel J., Martin Y., Derriennic F., Penneaufondbonne D. (1997). Occupational \& personal risk factors for carpal tunnel syndrome in industrial workers. Scandinavian Journal of Work Environ Health, 23, p. 364369.

[3] Ellist T. (1999) Implementing job rotation. Occupational health and Safety, 68 (1) p. $82-84$.

[4] Edwards, R.H.T. Human muscle function and fatigue. Londres. Edic. Whelan, 1981

[5] Bigland-Ritchie, B., Jones, D.A., Hosking, G.P., Edwards, R.N.T. Central and peripheral fatigue in sustained maximum voluntary contractions of human quadriceps muscle. Clin. Sci. Molec. Med., 609-14, 1978.

[6] Bigland-Ritchie, B.; Donovan, E.F. \& Roussos, C.S. Conduction velocity EMG power spectrum changes in fatigue of sustained maximal efforts. J. Appl. Physiol. :1300-1305, 1981. 
[7] Grandjean, E. Manual de Ergonomia - Adaptando o trabalho ao homem: Bookmam, 4o ed, 1998

[8] Grandjean,, E. Fitting the task to the man. London: Taylor \& Francis, 1987

[9] Denadai, B.S. Ïndices fisiológicos de avaliação aeróbia. Conceitos e aplicações. Ribeirão Preto, B.S.D., 1999, 76p.

[10] Farinatti, Paulo de Tarso V. \& Monteiro, Walace David; Fisiologia e Avaliação Funcional; 1a; Sprint; Rio de Janeiro; 1992

[11] Hollman, W.; Hettinger, Th. Medicina do Esporte. São Paulo: Manole, 1983.

[12] Mader, A., Liessen, H., Heck, H., Philippi, H., Rost, R., Schuch, P.,AND Hollmann, W.: Zur Beurteilung der sportartspezifischen Ausdauerleistungsfähigkeit im Labor. Sporzt Sportmed. 27:80-88, 109-112, 1976.

[13] Wells, J.G., Balke, B., and Van Fossan, D.D.: Lactic acid accumulation during work. A suggested Standardization of work classification. J Appl Physiol. 10: 51-55, 1957

[14] Fox, Edward L. \& Mathews, Donald K.; Bases Fisiológicas da Educação Física e dos Desportos; 3a; Guanabara; Rio de Janeiro; 1986
[15] Saint-Jacques, Y. (2001). La transformation des tâches dans les nouvelles formes d'organisation du travail. Congrès de la SELF, Montréal, Québec, 3-5 oct.

[16] Mac Leod D., Kennedy E. (1993). Job Rotation System. Site oficial: <http://www.macleod.com>.

[17] Slack N., Chambers S., Harland C., Harrison A. and Johnston R.,Operations Management, Pitman, 1995

[18] Henderson C. Ergonomic job rotation in poultry processing. Advance in Industrial Ergonomics and Safety: 256- 269, 1992.

[19] CANADIAN CENTRE for OCCUPATIONAL HEALTH and SAFETY. Job Desing - How it contributes to occupational health and safety, 146p., 1992 COUTO, Hudson de Araújo. Ergonomia Aplicada ao Trabalho - O Manual Técnico da Máquina Humana. v.2 Belo Horizonte: Ergo, 1995. 383p.

[20] Kuiser, P., Visser, B., Kemper H. Effect of Job Rotation on the physical workload. International Ergonomics (6): 66-68, 1994.

[21] Anne Gerling, A. Aublet-Cuvelier, Michel Aptel (2003) Comparaison de deux systèmes de rotation de postes dans le cadre de la prévention des troublesmusculosquelettiques, Pistes, vol 5 n2 Decembre 2003. 